\title{
Porównanie skuteczności krioterapii miejscowej stosowanej samodzielnie i modyfikowanej metodą Kinesiology Taping u pacjentów z przewlekłymi dolegliwościami bólowymi i ograniczeniem ruchomości odcinka szyjnego kręgostupa
}

\author{
Comparison of effectiveness of local cryotherapy alone and modified \\ Kinesiology Taping method in patients with chronic pain and limitation \\ in cervical spine mobility
}

\author{
Żaneta Ciosek ${ }^{1 凶}$, Aleksandra Szylińska', Łukasz Kopacz ${ }^{2}$, Karolina Kot ${ }^{3}$, Iwona Rotter ${ }^{1}$ \\ ${ }^{1}$ Pomorski Uniwersytet Medyczny w Szczecinie, Zakład Rehabilitacji Medycznej i Fizjoterapii Klinicznej, ul. Żołnierska 54, 71-210 Szczecin \\ ${ }^{2}$ Pomorski Uniwersytet Medyczny w Szczecinie, Studium Doktoranckie przy Samodzielnej Pracowni Propedeutyki i Fizykodiagnostyki Stomatologicznej, \\ al. Powstańców Wlkp. 72, 70-111 Szczecin \\ ${ }^{3}$ Pomorski Uniwersytet Medyczny w Szczecinie, Katedra i Zakład Biologii i Parazytologii Medycznej, al. Powstańców Wlkp. 72, 70-111 Szczecin \\ $\triangle$ ciosekzaneta@gmail.com
}

\begin{abstract}
Introduction: While pain in the cervical spine is less common than lower back pain, $33 \%$ of people experience neck pain in their life. The techniques for reducing the pain are local cryotherapy and Kinesiology Taping (KT).

The aim of the study was to compare the effectiveness of local cryotherapy applied separately, and a modified KT method in patients with chronic pain and limitation in cervical spine mobility. Materials and methods: The study group comprised 64 patients: 23 men and 41 women with chronic pain and limitation in cervical spine mobility. The patients were randomly divided into two groups of 32 people. In the first group, the patients, 20 female and 12 male, were subjected to 10 local cryotherapy treatments (without weekends), examination of mobility of the cervical spine (on the first and the last day of study) and KT. In the second
\end{abstract}

group, the participants, 21 female and 11 male, underwent 10 local cryotherapy treatments and examination of mobility of the cervical spine.

Results: The analysis of patients qualified for cryotherapy and KT after 10 treatments showed the biggest increase, $0.51 \mathrm{~cm}$ $(p<0.001)$, in the range of motion in the direction of extension. The difference of rotation to the left was $0.43 \mathrm{~cm}(\mathrm{p}<0.001)$, rotation to the right was $0.42 \mathrm{~cm}(\mathrm{p}<0.001)$, the lateral bending to the right was $0.41 \mathrm{~cm}(\mathrm{p}<0.001)$, and the lateral bending to the left was $0.4 \mathrm{~cm}(\mathrm{p}<0.001)$.

Conclusion: Greater increase in the range of motion of the cervical spine is obtained after the application of cryotherapy and KT than local cryotherapy alone.

Keywords: pain; cervical spine; Kinesiology Taping; local cryotherapy.

\begin{abstract}
ABSTRAKT
Wstęp: Ból górnego odcinka kręgosłupa występuję u 33\% populacji i pod względem dolegliwości bólowych kręgosłupa plasuje się na drugim miejscu, tuż za bólami w odcinku lędźwiowo-krzyżowym. Jednym ze sposobów leczenia dolegliwości bólowych jest zabieg krioterapii miejscowej, jak również nowatorska metoda Kinesiology Taping (KT).

Celem badań było porównanie skuteczności krioterapii miejscowej stosowanej samodzielnie i modyfikowanej metodą KT u pacjentów z przewlekłymi dolegliwościami bólowymi i ograniczeniem ruchomości odcinka szyjnego kręgosłupa.

Materiały i metody: W badaniu wzięło udział 64 pacjentów - 23 mężczyzn i 41 kobiet z przewlekłymi dolegliwościami bólowymi oraz ograniczeniem ruchomości odcinka szyjnego. W sposób losowy dokonano podziału na dwie grupy po 32 osoby. Pierwszą grupę stanowiło 12 mężczyzn i 20 kobiet, którzy zostali poddani 10 zabiegom krioterapii miejscowej (wykluczając weekend),
\end{abstract}

badaniu zakresu ruchomości (w pierwszy i ostatni dzień badania), jak również aplikacji KT. W grupie drugiej znajdowało się 11 mężczyzn i 21 kobiet poddanych 10 zabiegom krioterapii miejscowej i 2-krotnemu badaniu ruchomości odcinka szyjnego kręgosłupa.

Wyniki: W analizie pacjentów zakwalifikowanych do zastosowania krioterapii i aplikacji KT po 10 zabiegach zaobserwowano największą poprawę zakresu ruchomości w kierunku wyprostu 0 0,51 cm $(\mathrm{p}<0,001)$. W kierunku skrętu w lewo różnica wyniosła $0,43 \mathrm{~cm}(\mathrm{p}<0,001)$, skrętu w prawo - 0,42 cm ( $<<0,001)$, skłonu w prawo $-0,41 \mathrm{~cm}(\mathrm{p}<0,001)$ i skłonu w lewo - 0,4 cm $(\mathrm{p}<0,001)$. Wnioski: Większy wzrost zakresu ruchomości odcinka szyjnego uzyskuje się po zastosowaniu krioterapii i aplikacji KT niż po samym zabiegu krioterapii miejscowej.

Słowa kluczowe: ból; odcinek szyjny; Kinesiology Taping; krioterapia miejscowa. 
W dobie szybkiego postępu i rozwoju technologicznego dolegliwości bólowe kręgosłupa szyjnego i lędźwiowo-krzyżowego stały się istotnym problemem epidemiologiczno-terapeutycznym naszego społeczeństwa [1]. Ból górnego odcinka kręgosłupa występuję u 33\% populacji i pod względem częstości dolegliwości bólowych kręgosłupa plasuje się na drugim miejscu, tuż za bólami w odcinku lędźwiowo-krzyżowym. Biomechanika tego odcinka oraz jego budowa anatomiczna przyczyniają się do powstawania przeciążeń. Przeprowadzono liczne badania, których wyniki dowodzą, że przyczyną bólu w odcinku szyjnym w 90\% przypadków jest krążek międzykręgowy i zachodzące procesy zwyrodnieniowe usytuowane w chrząstkach i stawach międzykręgowych [2]. Do innych przyczyn zaliczyć można: zmiany powstałe po urazach, zmiany nowotworowe, zmiany zapalne, osteoporozę oraz choroby układowe tkanki łącznej [3].

Jednym ze sposobów leczenia dolegliwości bólowych jest zabieg krioterapii miejscowej, jak również nowatorska metoda plastrowania Kinesiology Taping (KT). Zabieg krioterapii stanowi jedną z form zimnolecznictwa i polega na pobudzeniu organizmu pacjenta krótkim, ale bardzo intensywnym miejscowym schłodzeniem określonej części ciała. Do zabiegów krioterapii miejscowej wykorzystuje się ciekły azot, którego temperatura u wylotu dyszy wynosi od $-160^{\circ} \mathrm{C}$ do $-196^{\circ} \mathrm{C} \mathrm{lub}$ dwutlenek węgla, którego temperatura wynosi ok. $-78^{\circ} \mathrm{C}$. Zabieg trwa 1-3 $\min$ [4].

W wyniku działania niskich temperatur następuje skurcz naczyń krwionośnych, jak również obniżenie ciepłoty ciała na poziomie skóry, tkanki podskórnej i w mniejszym stopniu mięśni. W ciągu kilku minut po zabiegu obserwuje się rozszerzenie naczyń krwionośnych i wzrost przepływu krwi. Odruch ten jest podstawowym mechanizmem termoregulacji po zabiegach z zastosowaniem temperatur kriogenicznych i utrzymuje się zwykle ok. 3-6 godz. Działanie zimna powoduje wiele korzystnych zmian w organizmie, m.in. utlenia i odżywia tkanki (mięśnie, więzadła, skóra), blokuje silne bodźce bólowe w mechanizmie tzw. zamykania bramki bólowej na poziomie rdzenia kręgowego, a następnie wzgórza, wywiera działanie, jak również powoduje wzrost stężenia beta-endorfiny [5, 6].

Kinesiology Taping został opracowany w latach 70. XX w. przez japońskiego chiropraktyka, prezydenta Towarzystwa Kinesiotapingu Narodowej Szkoły Chiropraktyków, absolwenta Uniwersytetu w Meiji i Narodowej Szkoły Chiropraktyków w Chicago - dra Kenzo Kase. Stworzył on taśmę, której kluczowym celem jest wspomaganie procesu usprawniania w wielu jednostkach chorobowych. Główną funkcją plastra jest m.in. redukcja bólu, rozluźnienie napiętych mięśni, poprawa funkcji nadmiernie rozciągniętych mięśni oraz zwiększenie zakresu ruchu. Technika naklejania taśmy na ciało dopasowana jest do potrzeb terapeutycznych. Każda z metod spełnia odrębne zadania i uzależniona jest od miejsca aplikacji taśmy [7, 8]

Celem badań było porównanie skuteczności krioterapii miejscowej stosowanej samodzielnie i modyfikowanej metodą KT u pacjentów z przewlekłymi dolegliwościami bólowymi i ograniczeniem ruchomości odcinka szyjnego kręgosłupa.

\section{MATERIAtY I METODY}

W badaniu wzięło udział 64 pacjentów: 23 mężczyzn i 41 kobiet, którzy z powodu przewlekłych dolegliwości bólowych oraz ograniczenia ruchomości odcinka szyjnego zgłosili się do Poradni Rehabilitacyjnej w Szczecinie. Przedział wiekowy wśród badanych wynosił 61-85 lat (średnia 70,6). Kryteriami wykluczającymi z udziału w badaniu były: choroby nowotworowe, choroby zapalne, dolegliwości bólowe i ograniczenie ruchomości odcinka szyjnego trwające krócej niż pół roku. W sposób losowy dokonano podziału na dwie grupy po 32 osoby.

Pierwszą grupę stanowiło 12 mężczyzn i 20 kobiet, którzy zostali poddani 10 zabiegom krioterapii miejscowej (wykluczając weekend), badaniu zakresu ruchomości (w 1. i ostatnim dniu badania), jak również aplikacji KT metodą mięśniową zgodnie z metodyką. Plaster w kształcie litery „Y” został naklejony 2-krotnie (w 1. i 5. dniu badania). Aplikację wykonano w pozycji siedzącej. Baza została naklejona na wyrostku kolczystym Th4, następnie po wykonaniu maksymalnego zgięcia w odcinku szyjnym zostały naklejone ogony w kierunku wyrostków sutkowatych (bez naciągania taśmy). Zakończenia ogonów zostały doklejone po powrocie do pozycji neutralnej.

W drugiej grupie znajdowało się 11 mężczyzn i 21 kobiet poddanych 10 zabiegom krioterapii miejscowej i 2-krotnemu badaniu ruchomości odcinka szyjnego kręgosłupa (jak wyżej). Do oceny stopnia odczuwanego przez pacjentów bólu w 1. i 10. dniu badania użyto wizualno-analogowej skali VAS (Visual Analogue Scale) w zakresie 0-10 (0 - bez bólu, 10 - ból nie do wytrzymania), na której badani zaznaczali natężenie odczuwanego bólu.

W obu grupach krioterapia miejscowa wykonywana była 1 raz w ciągu dnia za pomocą kriostymulatora działającego w systemie ciekłego azotu. Miejsce poddawane zabiegowi, ze względu na bezpieczeństwo pacjenta, było dokładnie osuszone, wylot dyszy znajdował się w odpowiedniej odległości (co najmniej $10 \mathrm{~cm}$ ) od ciała, a poruszanie dyszą krioaplikatora było regulowane we współpracy z badanym, aby strumień zimna nie padał stale na jedną okolicę miejsca zabiegowego. Zabieg trwał 3 min.

Badanie ruchomości kręgosłupa w odcinku szyjnym zmierzono w pozycji siedzącej, swobodnej, z głową ustawioną w płaszczyźnie frankfurckiej (wzrok skierowany na wprost):

1. Zgięcie: centymetr został przyłożony do guzowatości potylicznej zewnętrznej, jak również wyrostka kolczystego VII kręgu szyjnego. Następnie polecono badanemu wykonanie maksymalnego zgięcia głowy do przodu i ponownie dokonany został pomiar między wymienionymi punktami. Różnica została uznana jako miara ruchomości. Szacunkowe normy zakresu ruchu zgięcia w przedziale wiekowym 61-85 lat wynoszą $2 \mathrm{~cm}$.

2. Wyprost: centymetr został przyłożony do szczytu bródki, jak również do wcięcia jarzmowego rękojeści mostka. Następnie polecono badanemu wykonanie maksymalnego wyprostu do tyłu i ponownie dokonany został pomiar między wymienionymi punktami. Różnica została uznana jako miara ruchomości. 
Szacunkowe normy zakresu ruchu wyprostu w przedziale wiekowym 61-85 lat wynoszą 5,5 cm.

3. Skłony w bok (lewa + prawa strona): centymetr został przyłożony do wyrostka sutkowatego kości skroniowej i wyrostka barkowego łopatki. Następnie polecono badanemu wykonanie maksymalnego skłonu w bok (dokładnie w płaszczyźnie czołowej), w lewą lub prawą stronę (w prawą stronę, jeśli centymetr przyłożony był do lewego wyrostka sutkowatego kości skroniowej, a w lewą stronę, jeśli centymetr przyłożony był do prawego wyrostka sutkowatego kości skroniowej) i ponownie dokonany został pomiar między wymienionymi punktami. Różnica została uznana jako miara ruchomości. Szacunkowe normy zakresu ruchu wyprostu w przedziale wiekowym 61-85 lat wynoszą $4 \mathrm{~cm}$.

4. Skręty (lewa + prawa strona): centymetr został przyłożony do szczytu bródki i wyrostka barkowego łopatki. Następnie polecono badanemu wykonanie maksymalnego skrętu głową w prawą lub lewą stronę (w prawą stronę, jeśli centymetr przyłożony był do lewego wyrostka barkowego łopatki, a w lewą stronę, jeśli centymetr przyłożony był do prawego wyrostka barkowego łopatki) i ponownie dokonany został pomiar między wymienionymi punktami. Różnica została uznana jako miara ruchomości. Szacunkowe normy zakresu ruchu wyprostu w przedziale wiekowym 61-85 lat wynoszą $6 \mathrm{~cm}[9]$.

Do analizy statystycznej danych uzyskanych w wyniku przeprowadzonych badań wykorzystano program Statistica 12 (StatSoft, Inc. Tulsa, OK, USA). Do oceny normalności rozkładu stosowano test Shapiro-Wilka. Do oceny istotności statystycznej wykorzystano test t-Studenta dla prób zależnych w przypadku stwierdzenia normalności rozkładu zmiennej losowej lub test Wilcoxona, jeśli rozkład odbiegał od normy. W porównaniach między grupami w zależności od zastosowanej rehabilitacji wykorzystano głównie test t-Studenta dla prób niezależnych lub test U Manna-Whitneya. Istotność statystyczna została określona przy wartości $\mathrm{p}<0,05$.

\section{WYNIKI}

Przeprowadzoną ocenę statystyk opisowych badanych zakresów ruchomości oraz dolegliwości bólowych odcinka szyjnego kręgosłupa przed rehabilitacją przedstawiono w tabeli 1. W ocenie zakresów ruchomości nie zaobserwowano istotnych statystycznie różnic pomiędzy średnimi w badanych grupach.

Po wykonanych 10 zabiegach ponownie przeprowadzono badanie zakresu ruchomości i wykazano w badanych grupach wzrost ruchomości odcinka szyjnego oraz spadek dolegliwości bólowych w odcinku szyjnym (tab. 2). Istotne różnice w średnich zaobserwowano w zakresie ruchu w kierunku wyprostu $(p=0,012)$, skrętu w lewo $(p=0,007)$ i skrętu w prawo $(\mathrm{p}=0,007)$.

W analizie pacjentów zakwalifikowanych do zastosowania krioterapii i aplikacji KT po 10 zabiegach zaobserwowano największe zwiększenie zakresu ruchomości w kierunku wyprostu o 0,51 cm $(p<0,001)$. W kierunku skrętu w lewo różnica wyniosła $0,43 \mathrm{~cm}(\mathrm{p}<0,001)$, skrętu w prawo $-0,42 \mathrm{~cm}$ $(\mathrm{p}<0,001)$, skłonu w prawo $-0,41 \mathrm{~cm}(\mathrm{p}<0,001)$ i skłonu

TABELA 1. Porównanie wartości zakresu ruchu odcinka szyjnego kręgosłupa oraz dolegliwości bólowych w zależności od zaplanowanej rehabilitacji na pierwszym spotkaniu

Pierwsze spotkanie

\begin{tabular}{|c|c|c|c|c|c|c|c|c|c|}
\hline & \multicolumn{4}{|c|}{ krioterapia i Kinesiology Taping } & \multicolumn{4}{|c|}{ krioterapia } & \multirow{2}{*}{$\mathrm{p}$} \\
\hline & średnie & SD & $\min$. & maks. & średnie & SD & $\min$. & maks. & \\
\hline Zgięcie & 1,92 & 0,68 & 0,60 & 3,10 & 1,98 & 0,78 & 0,80 & 4,00 & 0,748 \\
\hline Wyprost & 4,56 & 1,84 & 0,50 & 8,00 & 3,88 & 1,58 & 1,00 & 6,50 & 0,119 \\
\hline Skręt w lewo & 5,13 & 1,52 & 2,80 & 8,20 & 4,33 & 1,67 & 1,50 & 8,00 & 0,052 \\
\hline Skręt w prawo & 5,11 & 1,46 & 2,40 & 8,00 & 4,33 & 1,70 & 0,90 & 8,00 & 0,052 \\
\hline Skłon w lewo & 3,84 & 1,73 & 0,80 & 8,00 & 4,06 & 1,75 & 1,40 & 8,00 & 0,612 \\
\hline Skłon w prawo & 3,85 & 1,59 & 1,50 & 8,00 & 4,04 & 1,65 & 2,00 & 8,00 & 0,645 \\
\hline VAS & 5,34 & 1,31 & 3,00 & 9,00 & 4,97 & 1,33 & 3,00 & 9,00 & 0,110 \\
\hline
\end{tabular}

TABELA 2. Porównanie wartości zakresu ruchu odcinka szyjnego kręgosłupa oraz dolegliwości bólowych w zależności od przeprowadzonej rehabilitacji

\begin{tabular}{|c|c|c|c|c|c|c|c|c|c|}
\hline \multicolumn{10}{|c|}{ Po 10 zabiegach } \\
\hline & \multicolumn{4}{|c|}{ krioterapia i Kinesiology Taping } & \multicolumn{4}{|c|}{ krioterapia } & \multirow{2}{*}{$p$} \\
\hline & średnie & SD & $\min$. & maks. & średnie & SD & $\min$. & maks. & \\
\hline Zgięcie & 2,14 & 0,71 & 0,60 & 3,20 & 2,17 & 0,71 & 0,90 & 4,00 & 0,903 \\
\hline Wyprost & 5,06 & 1,78 & 0,50 & 8,00 & 3,99 & 1,53 & 1,20 & 6,50 & 0,012 \\
\hline Skręt w lewo & 5,55 & 1,39 & 3,00 & 8,50 & 4,50 & 1,62 & 1,50 & 8,00 & 0,007 \\
\hline Skłon w lewo & 4,23 & 1,60 & 1,50 & 8,00 & 4,13 & 1,74 & 1,50 & 8,00 & 0,817 \\
\hline Skłon w prawo & 4,27 & 1,46 & 2,00 & 8,00 & 4,20 & 1,71 & 2,20 & 8,00 & 0,882 \\
\hline VAS & 3,78 & 2,11 & 0,00 & 7,00 & 3,75 & 1,87 & 0,00 & 9,00 & 0,950 \\
\hline
\end{tabular}


w lewo - 0,4 cm ( $\mathrm{p}<0,001)$. Najmniejszą uzyskaną różnicą $0,22 \mathrm{~cm}$ w tej grupie pacjentów jest ruch zgięcia $(\mathrm{p}<0,001)$. Dolegliwości bólowe przed zabiegiem wynosiły 5,34 w skali VAS, a po zabiegach spadły do 3,78 ( $\mathrm{p}<0,001)$.

W ocenie pacjentów, u których wykonywana była tylko krioterapia, po 10 zabiegach wykazano największe zwiększenie zakresu ruchu w kierunku zgięcia o 0,2 cm $(\mathrm{p}<0,001)$. Różnica w kierunku skrętu w lewo i skrętu w prawo wyniosła $0,17 \mathrm{~cm}(\mathrm{p}<0,001)$, natomiast skłonu $\mathrm{w}$ prawo $-0,16 \mathrm{~cm}$ $(\mathrm{p}<0,001)$, wyprostu $-0,11 \mathrm{~cm}(\mathrm{p}<0,001)$ oraz skłonu w lewo $0,07 \mathrm{~cm}(\mathrm{p}<0,001)$. Dolegliwości bólowe spadły o 1,22 w skali $\operatorname{VAS}(\mathrm{p}<0,001)$.

\section{DYSKUSJA}

Obecnie istnieje wiele metod i zabiegów pozwalających na zwiększenie zakresu ruchomości i redukcję dolegliwości bólowych. Dzięki zastosowaniu nowatorskich technik wprowadzanych na rynek i licznym publikacjom dotyczącym odpowiednio dobranej terapii efekty leczenia mogą być bardzo skuteczne.

Na podstawie badań własnych zaobserwowano pozytywny efekt stosowania zabiegu krioterapii miejscowej zarówno wykonywanej samodzielnie, jak i w połączeniu z aplikacją KT w poprawie zakresu ruchomości i zmniejszeniu dolegliwości bólowych odcinka szyjnego kręgosłupa. U pacjentów zakwalifikowanych do krioterapii i aplikacji KT po 10 zabiegach zaobserwowano większe zwiększenie zakresu ruchomości niż u osób po zastosowaniu tylko samej krioterapii: w kierunku wyprostu, różnica wynosiła 0,51 cm $(\mathrm{p}<0,001)$ skrętu w lewo $-0,43 \mathrm{~cm}(\mathrm{p}<0,001)$, skrętu w prawo $-0,42$ $\mathrm{cm}(\mathrm{p}<0,001)$, skłonu w prawo $-0,41 \mathrm{~cm}(\mathrm{p}<0,001)$ i skłonu w lewo $-0,4 \mathrm{~cm}(\mathrm{p}<0,001)$. Wyniki badań własnych są zgodne z badaniami innych autorów, którzy poddali ocenie wpływ zabiegu krioterapii miejscowej lub metody KT na dolegliwości bólowe i zakres ruchomości kręgosłupa.

Kopacz i wsp. przeprowadzili badania na grupie 36 studentów z przewlekłymi dolegliwościami bólowymi odcinka szyjnego. Po zastosowaniu aplikacji KT nastąpiło zmniejszenie natężenia bólu, a zakres ruchu zgięcia i wyprostu uległ znacznej poprawie. Autorzy oprócz techniki mięśniowej naklejali również taśmę metodą więzadłową, czego nie zastosowano w badaniach własnych [10]. Chen i wsp. przeprowadzili 2-tygodniowe badania w 2012 r., które polegały na naklejeniu u 21 pacjentów taśmy KT metodą powięziową, a u 22 osób placebo KT. U wszystkich badanych zdiagnozowano ból w dolnej części pleców kręgosłupa. Grupa z prawdziwą aplikacją KT po 2 tyg. wykazała znacząco lepsze wyniki w redukcji silnych dolegliwości bólowych niż grupa z naklejonym placebo. Warto podkreślić, że u osób ze średnim natężeniem bólu nie odnotowano żadnej różnicy [11]. Woźny i wsp. na podstawie badań chorych z zespołami bólowymi odcinka lędźwiowo-krzyżowego kręgosłupa potwierdzili korzystny wpływ miejscowo stosowanego zimna na zmniejszenie dolegliwości bólowych i poprawę zakresu ruchów. Dotyczyło to zwłaszcza osób, u których krioterapia została połączona z innymi metodami kinezyterapeutycznymi [12]. Podobne wyniki otrzymali Boerner i wsp. Na podstawie przeprowadzonej analizy statystycznej uzyskanych wyników odnotowali wyraźny wpływ krioterapii na obniżenie natężenia bólu i zwiększenie zakresu ruchów, zwłaszcza odwodzenia i rotacji zewnętrznej chorego stawu ramienno-łopatkowego [13].

\section{WNIOSKI}

Po zastosowaniu 10 zabiegów krioterapii lub krioterapii połączonej z aplikacją Kinesiology Taping obserwuje się zwiększenie zakresu ruchu w odcinku szyjnym kręgosłupa. Większy wzrost zakresu ruchomości odcinka szyjnego uzyskuje się po zastosowaniu krioterapii i aplikacji KT niż po samym zabiegu krioterapii miejscowej. Po zastosowaniu samej krioterapii lub krioterapii i aplikacji KT uzyskuje się spadek dolegliwości bólowych w skali VAS.

\section{PIŚMIENNICTWO}

1. Tomik B. Leczenie zespołów bólowych kręgosłupa. Terapia 2003;11(4):3942.

2. Barczyk K, Skolimowski T, Jasiński R, Stefański G, Hawrylak A. Wpływ zmian zwyrodnieniowych kręgosłupa szyjnego na zaburzenia czynnościowe narządu ruchu kobiet w średnim wieku. Fizjoterapia 2006;14(1):538.

3. Mikołajczyk E, Jankowicz-Szymańska A, Guzy G, Maicki T. Wpływ kompleksowej fizjoterapii na stan funkcjonalny pacjentek z dolegliwościami bólowymi odcinka szyjnego kręgosłupa. Hygeia Public Health 2013;48(1):73-9.

4. Lubkowska A. Zastosowanie krioterapii w chorobach przewlekłych. Fam Med Prim Care Rev 2013;15(2):233-9.

5. Bieńkowska A, Molski P, Dzierżanowski M, Bułatowicz I, Hagner W. Ból a krioterapia w kompleksowym leczeniu schorzeń narządu ruchu. Kwart Ortop 2006;4:311-4.

6. Miller E. Porównanie skuteczności działanie krioterapii miejscowej i krioterapii ogólnoustrojowej w bólu przewlekłym. Fizjoter Pol 2006;6(1):27-31.

7. Kase K, Wallis J, Kase T. Clinical therapeutic applications of the Kinesio Taping method. 3rd ed. Tokyo: Ken Ikai; 2003. p. 2-5.

8. Ciosek Ż, Kopacz Ł, Samulak Ł, Kaźmierczak A, Rotter I. Wpływ kinesiotapingu na dolegliwości bólowe odcinka lędźwiowo-krzyżowego kręgosłupa. Pomeranian J Life Sci 2015;61(1):115-9. doi: 10.21164/pomjlifesci.63.

9. Zembaty A. Kinezyterapia. Kraków: Wyd. Kasper; 2003. p. 152-7.

10. Kopacz Ł, Lietz-Kijak D, Perz A, Kubala E, Strzelecka P, Kijak E, et al. Zastosowanie metody fizjoterapeutycznej Kinesiology Taping w leczeniu dolegliwości bólowych odcinka szyjnego kręgosłupa wśród młodych stomatologów. Fizjoter Pol 2015;15(3):36-44.

11. Chen SM, Alexander R, Kai Lo S, Cook J. Effects of functional fascial taping on pain and function in patients with non-specific low back pain: a pilot randomized controlled trial. Clin Rehabil 2012;26(10):924-33.

12. Woźny A, Kujawa J, Cieszyński I, Gworys K, Puzder A. Ocena skuteczności przeciwbólowej kinezyterapii metodą McKenziego skojarzonej z krioterapią miejscową u chorych z zespołami bólowymi odcinka lędźwiowo-krzyżowego kręgosłupa. Kwart Ortop 2006;1:63-9.

13. Boerner E, Brzyk R, Bienias-Jędrzejewska M. Ocena skuteczności krioterapii miejscowej w leceniu zespołu bolesnego barku. Acta Bio-Opt Inform Med 2007;1(13):54-6 